\title{
Soundscapes, Sonic Cultures, and American Studies
}

\section{Introduction to the Special Issue}

W hat happens when we imagine the sonic worlds of literary texts, when we focus on voice in film, or when we study the sound of social protest? How can we integrate sound studies into our academic practices? How does sound relate to space and place? How can American studies scholars understand the link between sonic and social relations? Music, voices, noise, and silence are constitutive elements of phenomena that we as American studies scholars regularly investigate. However, in contrast to the well-established prominence of visual culture studies, sound features less prominently in our field's research-an oversight (pardon the pun!) this issue of JAAAS seeks to remedy.

The essays presented here originated with the $42^{\text {nd }}$ annual convention of the Austrian Association for American Studies, which was held at the University of Graz in November 2015. The conference theme, "Soundscapes and Sonic Cultures in America," invited speakers and listeners to contemplate how the variegated concerns of sound studies resonate with our interdisciplinary field and its numerous outlooks and theories. Speakers discussed sounds such as human voices, performed music, as well as naturally produced and technologically based noises; they also analyzed the characteristics and functions of silence. They contemplated how such sounds relate to a particular space or place and its inhabitants, and how this relation can be interpreted from perspectives within American studies. Furthermore, presenters explored the poetics of sonic cultures in order to address the particular functions of sounds in culture formation and cultural practice defined-for example-by region, ethnicity, gender, age, or musical taste. As the selection of essays in this special issue demonstrates, research on reception- or listener-oriented soundscapes was brought into dialog with research on production- or producer-oriented sonic cultures.

With this conference theme, the Austrian Association for American Studies acknowledged the growing bandwidth that the study of sound has been acquiring within the field of American studies and beyond. As is characteristic of the field, American studies has drawn on a wide range of disciplines, theories, and method- 
ologies to analyze issues of sound and culture. Publications in this area reflect the wide-ranging concerns of understanding sonic phenomena within specific disciplinary imaginaries. The journal Music, Sound, and the Moving Image has featured numerous articles on American films and popular music, and the American Studies Association's American Quarterly published a special issue on sound studies.' For the past decade, the open-access weekly Sounding Out! The Sound Studies Blog has been publishing peer-reviewed articles and scholarly conversations in myriad formats. As the annual 2019 "top ten" list on Sounding Out! amply demonstrates, sound studies-focused research revisits multiple key topics in American studies. Contributions address American popular music, critical race studies, the civil rights movement, Southern studies, new methods in urban studies, and black feminist literary theory. ${ }^{2}$ The aforementioned thematic issue of American Quarterly appeared simultaneously with a complementary website that provided access to many of the sounds and soundscapes discussed in its featured articles. Seeking to enhance the acoustic dimensions of scholarly research and publication, sound studies has devised pioneering digital and online media formats (as demonstrated by Sensate: A Journal for Experiments in Critical Media Practice). Furthermore, sound studies remains closely intertwined with research on other senses, as the breadth of references to scholars, publications, conferences, and resources on the website sensorystudies.org shows. In February 2016, the first issue of Sound Studies: An Interdisciplinary Journal was published with contributions by American studies scholars. These examples from a burgeoning field have contributed to firmly situating soundscapes and sonic cultures as essential to the American experience and to American cultural practices and vice versa.

In the 1960 and 1970s, the Canadian environmentalist and composer Raymond Murray Schafer began to study how sound (perception) serves as a crucial link between human beings and specific locations. He coined the term "soundscape," which has remained an influential and debated concept in sound studies to date. Adopting a spatial metaphor for aural perception via the allusion to "landscape," Schafer studied specific environments through the entire conglomerate of their audible features. According to him, "The home territory of soundscape studies will be the middle ground between science, society and the arts."3 Ever since the publication of Schafer's seminal work The Tuning of the World (1977), the term "soundscape" has undergone a process of critique and modification that reflects characteristic concerns of the various fields that participate in sound studies (for details, see Mark M. Smith's discussion in this issue). This process has highlighted disciplinary affordances and predispositions which need to be addressed in order to make cross-disciplinary communication effective. Some contributions to this issue engage explicitly with Schafer's term, both with its original, antimodernist version and with more 


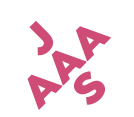

Soundscapes, Sonic Cultures, and American Studies

recent renditions; others employ different critical terminologies. Jointly, the set of articles showcases how scholars of sound shed light on hitherto ignored sonic features that contribute to a clearer sense of both long-standing and more recent American studies concerns: the multiplicity of historical narratives, the conceptualization and practice of core political values, and acts of pushing the envelope in an effort to develop innovative aesthetic forms in particular media as well as medium combinations.

One outlook that fits well into American studies trajectories is the contextualization of each soundscape within an "intellectual-historical milieu" which reveals the soundscape to be "an artefact of a set of dominant ways of organizing sonic space.". Fascinatingly, this method facilitates approaching soundscapes from at least two perspectives: first, one can study geographic locations through their sonic characteristics and, second, one can study how composed sounds create or at least evoke specific cultural spaces. In both cases, soundscapes rely on "sociogenesis" in their constructedness, ${ }^{5}$ which again indicates the closeness of the concept to a cultural studies perspective on social practices including the creation, distribution, and reception of art(ifacts).

The disciplinary breadth inherent in the forty talks given at the conference and in the contributions featured in this special issue clearly affirm the reciprocal relevance of sound studies and American studies. Accordingly, the essays presented here illustrate that the aural has been emerging as a crucial factor within research on the ways in which experiences are mediated and witnessed. Sounds have thus assumed growing importance within scholars' awareness of the sensory complexity of cultural practices and human-made representations.

As demonstrated in his keynote lecture and his contribution to this special issue, Mark M. Smith's research as a historian, particularly of the Civil War and of the Southern states of the U.S., has been pathbreaking in sensory studies. His work neatly locks arms with current American studies developments such as the necessity of oceanic perspectives. It is not sufficient, he argues, to study soundscapes on land, but-in many historical contexts-scholars must research "aquatic and terrestrial soundscapes" in conjunction with one another. ${ }^{6}$ Sound studies across disciplines has, from its beginnings, also challenged long-term hierarchical perspectives that privilege the visual over the aural.? This interest in rattling the cage of cultural traditions when it comes to competing sense perceptions illustrates ways in which, again, the social and the artistic intersect and in which multi- and interdisciplinary research is required to unravel the what, how, who, when, why, and to-what-effect of the sonic. As Trevor Pinch and Karin Bijsterveld point out, the field of sound studies allows us to scrutinize epistemologies and their possible consequences for the creation of technolo- 


\section{3}

Nassim W. Balestrini, Katharina Fackler, and Klaus Rieser

gies, for interpretative lines of thought, and for the appreciation of the sonic as an accepted diagnostic and knowledge-generating tool. ${ }^{8}$ At the same time, new ways of studying music have been leading scholars away from privileging the aesthetic over the social, and towards acknowledging-as Barry Shank made clear in his keynote and also argues in his contribution here-that experiencing sound goes far beyond the ostensibly metaphysical or at least immaterial dimensions of appreciating beauty. ${ }^{9}$

The papers of the 2015 AAAS conference covered areas such as analog and digital soundscapes, literary and musical sonic cultures, noise and silence, and-in the broadest sense-the ways in which sound-related phenomena resonate with core American studies concerns. Accordingly, the essays presented here provide insights into variegated areas within this broad range of research.

In "Sound + Bodies in Community = Music," Barry Shank demonstrates how cultural studies in general and sound studies in particular have reshaped cultural musicology. Far beyond broadly acknowledging that music is a social art, the questions posed and methods used in sound studies have opened up complex options for understanding the relational intricacies of musical sound, from its locations and conditions of production to the political impact of its reception. Awareness of the physical reality of music then adds to new perspectives on the extended impact of sound in space and time beyond acts of performance or practices of listening. As Shank explains, social traditions of inclusion and exclusion through sonic allegiances deserve further scrutiny, particularly because the dance/party performance context may differ sharply from the struggle-oriented and community-asserting features of, for instance, Sly and Family Stone's "I Want to Take You Higher." Ultimately, the sonic properties of music can forge a physical union which empowers concerted efforts.

Mark M. Smith's "In Praise of Discord: Beyond Harmony in Historical Acoustemology" elucidates the current state of sound studies from the perspective of a sensory historian, sounding a warning as to cul-de-sacs in the field and a clarion call for new directions. By characterizing the boom in historiography focused on aural features, Smith points out that the general thrill of engaging with an outlook that is comparatively new may lead to losing sight of the larger questions. In his "modest manifesto," Smith expresses his pleasure at the fact that sound studies have boomed in the recent past, but also issues a warning about a possible dilution of theoretical rigor. Thus, he calls for a thorough discussion of methodology and a continuous questioning of the status of the aural in historiography. But rather than sowing conflict, the essay exudes appreciation for what historical acoustemology can achieve. The suggested remedy is renewed attention to theory, method, and terminology, among them the very notion of "soundscapes," mentioned in our title and engaged by a range of our contributors. 
In her contribution, "Voice, Silence, and Quiet Resistance in Percival Everett's Glyph," Nathalie Aghoro traces the possibilities of voiceless resistance against racial determinism through an analysis of the protagonist Ralph's silence. As she points out, voice is a trope for protest and resistance in a number of black novels; and Glyph, with its focus on silence stemming from a refusal to speak, both participates in and enlarges the scope of this trope. Here, willful silence is a means of self-protection, a provocation, and a political statement. Beyond that, Aghoro also stresses that the novel constitutes a refusal of essentialist interpretation (as a "black" novel) and instead demands to be seen as a metareferential comment on the role of voice in literature as well as a philosophical intervention in the relation between writing and speech. This is partly realized in the creation of a literary soundscape in which various philosophers and writers engage in vernacular conversations.

In "The Timbre of Trash: Rejecting Obsolescence through Collaborative New Materialist Sound Production," Joe Cantrell places the work of three contemporary experimental musicians, Qubais Reed Ghazala, Curtis Rochambeau, and William Basinski, in a conversation with new materialist theories. The three artists Cantrell discusses make music with discarded objects ranging from cast-off electronic instruments to outdated medical units and aging magnetic tape. Throughout the creative process, these objects assert their own agency, opening up pathways for different, more reciprocal relationships between human beings and things, technology and ecology. As Cantrell argues, these relationships echo and complement the ideas of new materialist thinkers such as Jane Bennett, Karen Barad, and Rosi Braidotti, who encourage a move beyond subject-object binaries and emphasize humans' entanglement with and embeddedness in (rather than mastery of) the material world. Cantrell contends that, by resisting the built-in obsolescence of electronic products, these creative forms of collaborative sound production counteract the drive for the always new in American culture and encourage a more sustainable relationship with the material environment.

In her article "American Studies, Sound Studies, and Cultural Memory: Woody Van Dyke's San Francisco as a Sonic Contact Zone," Susanne Leikam carefully listens to the soundscapes of the popular musical film San Francisco, whose theme song advanced to one of San Francisco's official songs. She analyzes how the film, a product of the Depression era, sonically memorializes the 1906 San Francisco earthquake and fire, and exposes how the film's sonic imagination offers a highly selective kind of disaster memory. Leikam argues that while the actual earthquake was particularly disastrous for the city's poorer and nonwhite inhabitants, San Francisco sonifies a "disaster optimism" that presents the earthquake as "a social equalizer and a patriotic affirmation of American resilience." While the city before the earthquake and fires is characterized by noise, clamor, and tensions between different sonic tradi- 


\section{㳻}

Nassim W. Balestrini, Katharina Fackler, and Klaus Rieser

tions, the disaster resolves these tensions and unifies its citizens, who are now ready for Americanization and progress. Leikam shows that, as the song "San Francisco" has remained highly popular, our ears remain attuned to an idealized cultural memory.

Leopold Lippert's article "The Gendered Sounds of Revolutionary American Theater" analyzes the function of sound for the textual operation of a 1774 theatrical pamphlet and a 1777 play-texts that were apparently never performed in a theater and thus are characterized by "virtual theatricality." Through a careful reading of the textual properties (such as punctuation, retorts, genre conventions, and contemporary culture), Lippert endeavors to reveal the impact of "nagging female voices" on textual meaning. This study of the virtual sound of female voices reveals how politics intersects with gendered assumptions and configurations of femininity in early American theater. Grounded in theories and analyses of early American soundscapes, revolutionary and post-revolutionary politics, and gender in comedy, the author convincingly situates the sonic performance in these texts within their literary historical epoch. Furthermore, Lippert points out that an understanding of sound is essential for the reception and interpretation of these plays: depending on whether the reader interprets the female voice as hysterical or reasonable, the text changes from a misogynist to a proto-feminist outlook while it also shifts in its standpoint vis-à-vis the contemporary political landscape.

Roxana Oltean's article "Language ... Without Metaphor": Soundscapes and Worldly Engagements in Henry David Thoreau's Walden" provides a close reading of the soundscapes of Thoreau's Walden; Or, Life in the Woods (1854), in which he juxtaposes the sounds of nature with those of industrialization and technology. Thoreau's references to sound let us witness his engagement with modernity, since-as Oltean argues-he ultimately attempts to integrate the sounds of industrialization with those of the pastoral, alternating between harmony and dissonance. This essay invites the reader to think both about the advent of technology through sounds that have no basis in nature and about the human perception of and literary rendering of sound. Oltean's rereading of Walden through the lens of soundscapes illustrates synergies between literary studies (specifically on nature writing) and sound studies (specifically the study of sound in a bygone era devoid of recording devices) in the context of American studies.

Ralph Poole's article "Ta, te, ti, toe, too": The Horrors of the Harsh Female Voice in 1950 s Hollywood Comedies" starts out as a close contrastive reading of the films Singin' in the Rain (1952) and Born Yesterday (1950), both of which make fun of an incongruence between vision (the female star's physical appearance) and sound (her harsh voice and socio/dialect). Moreover, Poole elucidates the transition from silent to sound film (and, in particular, the musical), the gendering of voice, an ideology of 
cuteness, and later reading strategies. As he argues, through the lampooning of the harsh female voice, the films participate in the substitution of the unruly comedienne deemed to be offensive in the 1950 s film business with a cute/feminine type that fit snugly into heterosexual gender roles. The unfitting voice thus represents a self-confident, resistant female personality incommensurate with sound film, as much as the taming or elimination of the unruly character signals the waning reign of female stars. Like the twist ending of a film, Poole closes with an alternative reading which adds a new dimension to the feminist reading.

A. Elisabeth Reichel's "Sonic Others in Early Sound Studies and the Poetry of Edward Sapir: A Salvage Operation" links sound studies with anthropology and literature. Reichel analyzes the "literary acoustics" of two poems by the anthropologist-linguist Edward Sapir in light of early ethnographic constructions of hearing. These early-twentieth-century approaches associated hearing-and the people for whom the aural is supposedly the dominant sense-with an earlier, premodern way of life that was vanishing in a modern age dominated by sight. By suggesting that these people present an earlier stage of human development and by thus denying them coevalness in the present, they enact what Johannes Fabian would call an allochronism. Reichel argues that, while Sapir's scholarship was aligned with Franz Boas's project of challenging evolutionist conceptions of "the primitive," his poems echo the antimodern impulses of early sound studies. Her astute analyses demonstrate how Sapir's poems perform the gesture of a salvage operation that purports to preserve vanishing sounds and, concomitantly, the modern sense of hearing. In the process, however, they silence the voices of those people they claim to save from oblivion.

In his essay titled "The Motion and the Noise: Yoknapatawpha's Shifting Soundscape," Matthew D. Sutton analyzes how the changing soundscapes of the American South textured William Faulkner's writings. During Faulkner's time, industrialization and technology made the world louder, disrupting what many white Southerners, Faulkner included, had perceived as a pastoral quiet. The jukebox in particular, Sutton points out, blended European American and African American music, serving "as a repository of affect for the generation who would reject the quiescence." Sutton skillfully demonstrates that the African American character Lukas in Intruder in the Dust not only resists white supremacy through his refusal to speak up and defend himself when accused of a murder he did not commit. Lukas also uses a subtle reference to the popular blues song "That's Your Red Wagon" to defy white Southern perceptions of racial integration.

As this special issue demonstrates, the field of sound studies encourages research on the reciprocal relation between (un)composed sounds (and silences) in specific spaces, be they real or fictional. The notion of the situatedness of sound raises ques- 


\section{$*$}

Nassim W. Balestrini, Katharina Fackler, and Klaus Rieser

tions regarding the creation and development of sound imaginaries in local, regional, national, and transnational contexts. One corollary of inquiries into defining North American sonic cultures is the question as to how such cultures are perceived from within and from without, and as to how these perceptions interlace cultural stereotyping with sound styles and specific sounds. Similarly, studying sounds associated with ethnic groups, social classes, genders, genres, the production and consumption of commodities, and ever-evolving sound-recording and sound-producing technologies requires attention to the cultural implications of mediated sonic characteristics.

January 2020

Nassim W. Balestrini, Katharina Fackler, and Klaus Rieser DOl: 10.4706o/jaaas.v1i2.115

\section{Notes}

$1 \quad$ Kara Keeling and Josh Kun, eds., "Sound Clash: Listening to American Studies," special issue of American Quarterly 63, no. 3 (2011).

2 J. L. Stoever, "The Top Ten Sounding Out! Posts of 2019!” December 9, 2019, https:// soundstudiesblog.com/?s=Top+Ten.

3 R. Murray Schafer, "The Soundscape," in The Sound Studies Reader, ed. Jonathan Sterne (New York: Routledge, 2012), 96.

4 Jonathan Sterne, "Soundscape, Landscape, Escape," in Soundscapes of the Urban Past: Staged Sound as Mediated Cultural Heritage, ed. Karin Bijsterveld (Bielefeld: transcript Verlag, 2013), 184, DOI: 10.14361/transcript.9783839421796.181.

5 Ibid., 190.

6 Mark M. Smith, "Why Historians of the Auditory Urban Past Might Consider Getting Their Ears Wet," in Soundscapes of the Urban Past: Staged Sound as Mediated Cultural Heritage, ed. Karin Bijsterveld (Bielefeld: Transcript Verlag, 2013), 68, DOI: 10.14361/transcript.9783839421796.67.

7 See, for instance, Michael Bull and Les Back, "Introduction: Into Sound," in The Auditory Culture Reader, ed. Michael Bull (Oxford: Berg Publishers, 2003), 1-18.

8 Trevor Pinch and Karin Bijsterveld, "New Keys to the World of Sound," in The Oxford Handbook of Sound Studies, ed. Trevor Pinch and Karin Bijsterveld (Oxford: Oxford University Press, 2011), 11-12, DOI: 10.1093/oxfordhb/9780195388947.013.0010; see also Netzwerk "Hör-Wissen im Wandel," ed., Wissensgeschichte des Hörens in der Moderne (Berlin: de Gruyter, 2017), DOI: 10.1515/9783110523720.

9 See also Barry Shank, The Political Force of Musical Beauty (Durham, NC: Duke University Press, 2014). 